\title{
The effect of training the fathers to support their wives on stress and self-efficacy in mothers of premature newborns hospitalized in NICU: a quasi-experimental study
}

\author{
Zahra Hadian Shirazi ${ }^{1} \mathbb{B}$, Hamed Ghasemloo², Seyyed Mostajab Razavinejad ${ }^{3} \mathbb{0}$, Nasrin Sharifi' ${ }^{1}$ and \\ Shahpar Bagheri ${ }^{2 *}$ (1)
}

\begin{abstract}
Background: The birth of premature newborns and their separation from family due to their hospitalization in the Neonatal Intensive Care Unit (NICU) cause stress in the parents, especially mothers. We conducted this study aimed to evaluate whether training the fathers to support their wives impacts premature newborn mothers' stress and selfefficacy or not?

Methods: A quasi-experimental (before-after study) including one experimental and control group was used. Data were collected from Seventy-five parents with newborns hospitalized in NICU $(n=30)$ in the intervention and $(n=45)$ in usual care groups. Settings were the NICUs of the two international, educational, specialty, and subspecialty Nemazee and Hafez hospitals of the Shiraz University of Medical Science. Fathers in the intervention group learned how to support their wives and provide care for their premature newborns. The control group received the usual care. Mother's stress and self-efficacy were measured using validated questionnaires.

Results: Data analysis showed that the mean scores of mothers'stress and self-efficacy from pre-intervention to post-intervention were significantly decreased and increased respectively in the intervention group $(p<0.001)$. At the same time, there was no significant difference in the control group.

Conclusion: When fathers are trained to support their wives and do so, it relieves the stress and improves the mothers' self-efficacy, and has a direct effect on providing care to their premature newborns. Therefore, it is recommended that measures should be taken so that the fathers be present, participate in providing care, and support their wives and newborns in NICU.
\end{abstract}

Trial registration: IRCT20171130037691N1.

Keywords: Fathers, Mothers, Neonatal intensive care units, Self-efficacy, Stress, Training

*Correspondence: bagherishahpar@gmail.com; shbagheri@sums.ac.ir 2 Student Research Committee, Department of Nursing, School of Nursing and Midwifery, Shiraz University of Medical Sciences, Shiraz, Iran

Full list of author information is available at the end of the article

\section{Introduction}

Each year, approximately 15 million infants are born prematurely (i.e., less than 37 weeks of gestation) $[1,2]$. In Iran, about $10 \%$ of the births are related to premature babies, and the country is one of the regions with a high prevalence of preterm delivery [3]. Prematurity of newborns is now the second leading cause of death in 
children under 5 years of age and the single most important direct cause of death in the critical first month of life [4]. Birth of premature newborns, admission in the NICU, and separation of newborns from families impose high stress on parents [5]. The stress level of parents with premature infants is a psychological hazard for parents [6]. Mothers with premature newborns hospitalized in NICU who are separated from their infant immediately after delivery have high stress, anxiety, and depression level. This negatively affects their thinking and decisionmaking processes, leading to increased stress and a lack of self-efficacy in the newborn's care [7, 8]. The level of stress in mothers with premature newborns is higher than in fathers [9]. Mothers of premature infants have lots of stress and anxiety while their premature infants are in NICU. Therefore, there is an urgent need to relieve the mothers' anxiety and stress [10]. These mothers' stress and anxiety may lack appropriate newborn care ability [11, 12]. Parents attempt to support each other during the newborns' hospitalization, but unfamiliar and critical situations prevent them from playing their role correctly [13]. The relationship between the parents indirectly affects their association with the newborn [14]. For example, realizing their husbands' support and encouragement, mothers become more interested in performing their parental tasks $[15,16]$. Those mothers not receiving support from the newborn father have less interaction with their infant than their peers who receive such support [15]. Some studies show that supporting mothers by their husbands could help overcome these problems [1618]. This study aimed to train the fathers to support their wives and determine its effect on stress and self-efficacy in mothers of premature newborns hospitalized in the NICU.

\section{Methods}

\section{Study design}

This study had a quasi-experimental (pre-and post-intervention or before/after study) design with one experimental and control group and pre-and post-tests. We aimed to determine if training the fathers to support their wives would relieve stress and improve self-efficacy in the mothers of premature newborns hospitalized in the NICU. This design is considered to be of relatively high quality in the quasi-experimental study designs [19]. A quasi-experiment should be conducted when randomization is deemed not to be feasible [19-21]. In the current study, we selected a quasi-experimental design because randomization was not possible.

\section{Setting and participants}

We have conducted this study in two hospitals affiliated with Shiraz University of Medical Sciences in the south of Iran. This study was carried out from 03/21/2018 to $09 / 11 / 2018$. The research population included mothers with premature newborns hospitalized in NICU who were eligible for entering the study. Convenience sampling was done, and two groups of 45 and 30 parents were assigned to control and experimental groups, respectively. Sampling continued until the intended number of participants for each group was achieved.

The inclusion criteria for mothers and their newborns were premature newborns in the 32-37 weeks of pregnancy, lack of congenital anomaly in the newborn, lack of confrontation of mothers with other stressful events during the past 6 months, the outcome of a wanted pregnancy, lack of any record of using drugs effect on the mental health of the mothers, lowest elementary school literacy, a singleton infant, and lack of hospitalization record in NICU for their previous infants. Exclusion criteria were death or discharge of the newborn from the hospital during the study and lack of parents' willingness to continue participation in the research.

The sample size was calculated according to Arshadi et al. [18], $\alpha=0.05, \beta=0.2,1-\beta=0.8, \mathrm{~d}=14, q_{1}=0.4, q_{2}$ $=0.6$ and using following formula:

$$
\mathrm{n}=\frac{\left(z_{\propto}+z_{\beta}\right)^{2}\left(\frac{1}{q_{1}}+\frac{1}{q_{2}}\right)}{\frac{d^{2}}{s^{2}}}
$$

Considering a $10 \%$ loss, the sample size was 75 , of which 30 were placed in the intervention group and 45 in the control group. We sampled the two groups separately to prevent any diffusion of the intervention contents between the control and experimental groups. We primarily recruited participants for the control group and collected their data before implementing the intervention. After that, we recruited participants for the experimental group, delivered the intervention, and collected data from them at different time points.

\section{Measures}

In this study, we used the Persian version of two questionnaires to collect the data: PSS (perceived stress scale) and PMP S-E (Perceived Maternal Parenting SelfEfficacy). PSS is a validated questionnaire for measuring the stress level of parents of premature newborns hospitalized in NICUs. The questionnaire includes 26 items in 3 dimensions: 5 related to NICU environment, 14 about appearance and behavior of infants and special treatments, and seven on parents' relationship with newborns and playing their parental role. The items scoring are based on a 5-point Likert scale with a minimum score of zero and a maximum of 100 . Higher scores indicate a higher degree of stress. The questionnaire is reliable 
through Cronbach's alpha $\alpha=0.87$ for the whole questionnaire [22-24]. In a study performed by Beheshtipour et al. (2017), all subscales of the Persian version of PSS showed good internal consistency. $(\alpha=0.77-0.86)$ [25].

The PMP S-E questionnaire, a tool has developed by Barnes and Adamson-Macedo with 20 declarative items, measure parents' perceived feelings towards their selfefficacy. The instrument measures the parents' perception of their capabilities in understanding and providing care to premature hospitalized newborns and their sensitivity towards various tasks and levels in playing the parental role for a premature newborn. The tool's items were categorized as follows: 4 related to caring processes, 7 to motivational behaviors, 6 to the perception of behaviors and messages, and three related to situational behaviors. Scoring is within the range of 20 to 80 , and high scores show higher levels of self-efficacy. The PMP S-E is a reliable scale $(\alpha=0.91-0.96)$ [26]. Aliabadi et al. (2013) have used the questionnaire to evaluate the self-efficacy in mothers of hospitalized infants in several children's hospitals in Iran. The above study was showed good reliability with a Cronbach's alpha of 0.97 for the Persian version of PMP S-E [27].

\section{Procedure}

The Ethics Committee of the Shiraz University of Medical Sciences approved this study (IR.SUMS. REC.1396.112). Then, after trial confirmation at the Iranian Registry of Clinical Trials (IRCT) with the code IRCT20171130037691N1, the researchers started the sampling.

All procedures performed in this study complied with the institutional and national research committee's ethical standards and the 1964 Helsinki declaration and its later amendments or comparable ethical standards. We informed the Fathers and mothers who participated in the study about its purpose and procedure by face-toface explanations, and we obtained written consent from them. First, sampling for the control group was done. Data were collected using the socio-demographic and the PSS and PMP S-E questionnaires through face-toface interviews with mothers on the second day of the newborn's hospitalization a week later. Participants in the control group received the usual training care. After completion of the control group, we started to select the intervention group. The socio-demographic, PSS, and PMP S-E questionnaires were filled out in the intervention group using the abovementioned method.

\section{Intervention}

The experimental group's fathers received an educational support program consisting of two $90-\mathrm{min}$ face-to-face training sessions on the third and fourth day of the baby's hospitalization. Contents of intervention were based on the nursing resources in the infant care field $[28,29]$ and provided using PowerPoint, videos, and an infant manikin model. Training sessions were held in the teaching rooms of Hafez and Nemazee Educational Health Centers. The materials provided to the intervention group were as follows:

\section{First session}

Welcoming, explaining the purpose, preterm birth, premature newborns' status, and needs; explaining the NICU, health care staff, equipment, and usual therapeutic and nursing care provided in the ward; and answering participant questions.

\section{Second session}

Mothers' physical and mental changes after childbirth, the role of fathers in providing support and care of the mother and premature newborn (having skin-to-skin contact between parents and their newborn, massage, feeding, assuming the proper position, and changing a diaper) and answering to participant questions. Also, for better learning of fathers, a booklet and two pamphlets about the care of premature newborns and mothers and familiarity with neonatal intensive care unit provided for them. After training, the fathers began caring about their infants and giving support to the mothers. All fathers completed the training courses without loss to follow-up. In the cases of any need for complementary information, they were provided with possible telephone contact or met the researcher. The usual care for the control group was included information about prematurity and the infants' illness and giving a prognosis about the process of treatment, recovery of the baby, and introducing parents to the duties of the intensive care unit and staff.

\section{Statistical analysis}

We used SPSS 21. to analyze the data. Descriptive data were analyzed through tables and charts (mean and standard deviations). Inferential statistics included chisquare, paired, and independent $\mathrm{t}$-tests. PMP-SE has no dimension or category, but PSS can be categorized as very low $(\leq 20)$, low [21-40], moderate (41-60), high $(61-80)$, and very high-stress level $(80 \geq)$. Statistical significance was considered $p<0.05$.

\section{Results}

In this study,117 participants were examined for eligibility, 42 were excluded due to 34 not meeting inclusion criteria, and eight declined to participate. Among 75 mothers under the study, 30 (40\%) were in the intervention group and 45 (60\%) in the control group (Fig. 1). 


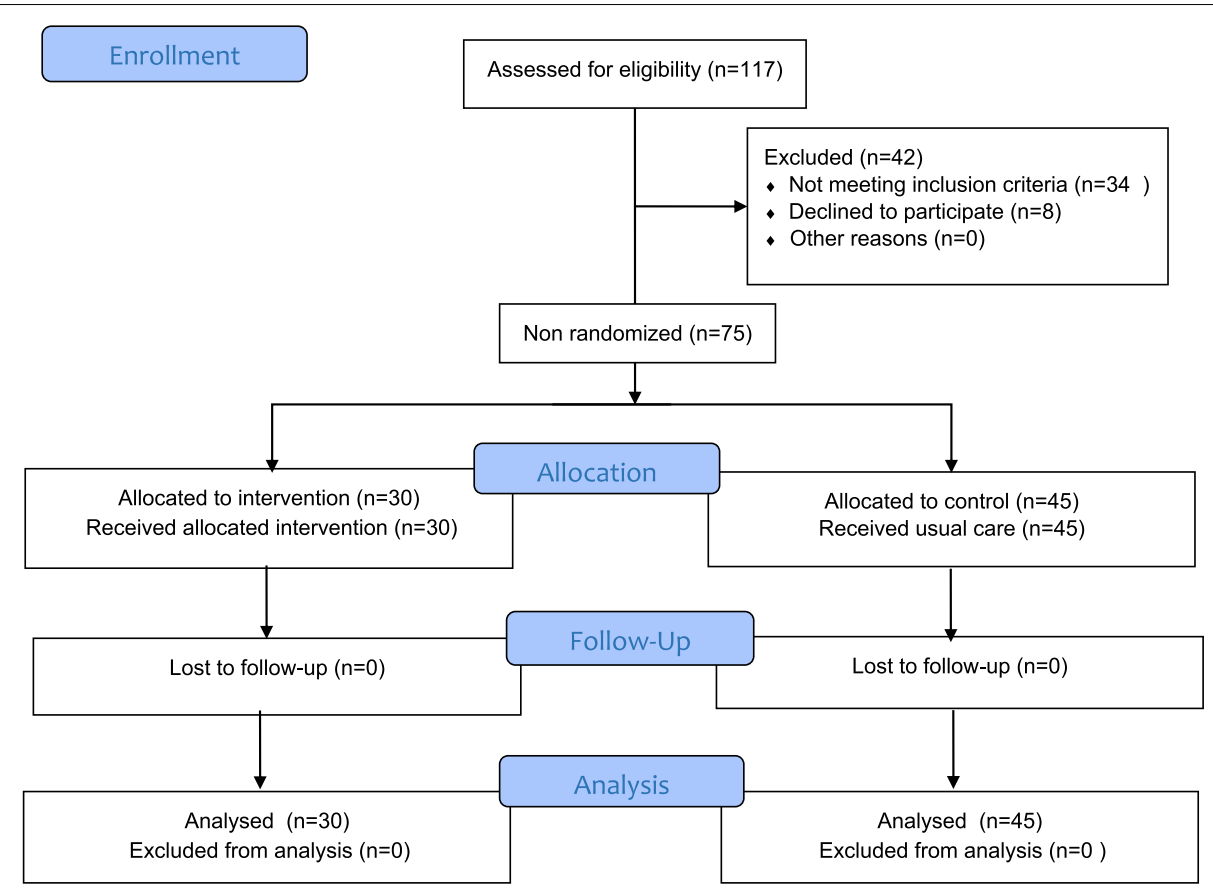

Fig. 1 Flow chart of the study

As shown in Table 1, both groups were homogeneous in terms of quantitative demographic variables (newborns' birth weight, pregnancy age, mothers' age, fathers' age), and qualitative demographic variables (newborns' gender, type of delivery, mothers' education level, mother's job, residence, being multiparous or nulliparous, miscarriage record, fathers' education level, and father's job). Statistical analysis showed no statistically significant difference $(p>0.05)$.

As the results of Table 2, There was no significant difference between the stress mean scores in the intervention and control groups before the intervention $(p=0.13)$. There was a significant difference between the stress mean score in the intervention and control groups after the intervention $(p<0.001)$. In the control group, the stress mean scores before and after the intervention were not significantly different $(p=0.07)$. However, in the intervention group, the stress mean scores before and after the intervention were $72.96 \pm 12.25$ and $57.50 \pm 6.29$, and the difference was statistically significant $(p<0.001)$.

There was no significant difference between the selfefficacy mean score in the controls and the intervention group before the intervention $(p=0.057)$. There was a significant difference between the self-efficacy mean scores in the control and experimental groups after the intervention $(p<0.001)$. In the control group, the mean self-efficacy scores before and after the intervention were not significantly different $(p=0.115)$. However, in the intervention group before and after the intervention, the mean self-efficacy scores were $60.83 \pm 4.77$ and 70 . $0 \pm 4.82$ respectively, with a statistically significant difference $(p<0.001)$. The results are presented in Table 3.

We used Wilcoxon signed ranks test to compare the two groups (Table 4, Fig. 2). The results showed that the stress levels before and after intervention in the studied groups were significantly different.

\section{Discussion}

The present study aimed to train the fathers to support their wives and determine its effect on the mothers' stress and self-efficacy scores in providing care to premature newborns hospitalized in NICU. The results showed that training fathers to support their wives reduced mothers' stress and increased self-efficacy in the care of premature newborns. The differences between the mean scores of stress and self-efficacy in the control group before and after the intervention were not statistically significant. After the intervention, the mothers' stress and self-efficacy scores decreased and increased in the intervention group. The difference observed in the intervention group before and after the intervention was statistically significant. Findings of numerous studies showed that interventions consisting of supportive (training-emotional) programs for parents of premature newborns reduced their stress 
Table 1 Distribution of demographic variables

\begin{tabular}{|c|c|c|c|c|}
\hline \multicolumn{2}{|l|}{ Group } & \multirow[t]{2}{*}{ Intervention } & \multirow[t]{2}{*}{ Control } & \multirow[t]{2}{*}{$P$ value } \\
\hline Variable & & & & \\
\hline \multirow[t]{2}{*}{ Newborns'gender } & Male & $14(46.7 \%)$ & $23(51.1 \%)$ & 0.70 \\
\hline & Female & $16(53.3 \%)$ & $22(48.9 \%)$ & \\
\hline \multirow[t]{2}{*}{ Type of delivery } & Normal vaginal delivery (NVD) & $12(40 \%)$ & $13(28.9 \%)$ & 0.31 \\
\hline & Cesarean section & $18(60 \%)$ & $32(71.1 \%)$ & \\
\hline \multirow[t]{3}{*}{ Mothers' education level } & Under the diploma & $7(23.3 \%)$ & $13(28.9 \%)$ & 0.25 \\
\hline & Diploma and Bachelor & $21(70 \%)$ & $24(53.3 \%)$ & \\
\hline & Master and Ph.D. & $2(6.7 \%)$ & $8(17.8 \%)$ & \\
\hline \multirow[t]{2}{*}{ Mother's job } & Employed & $5(16.7 \%)$ & $11(24.4 \%)$ & 0.42 \\
\hline & Unemployed & 25(83.3\%) & $34(75.6 \%)$ & \\
\hline \multirow[t]{2}{*}{ Being multiparous or nulliparous } & Nulliparous & $15(50 \%)$ & $25(55.6 \%)$ & 0.63 \\
\hline & Multiparous & $15(50 \%)$ & $20(44.4 \%)$ & \\
\hline \multirow[t]{2}{*}{ Abortion history } & Yes & $7(23.3 \%)$ & $12(26.7 \%)$ & 0.74 \\
\hline & No & $23(76.7 \%)$ & 33(73.3\%) & \\
\hline \multirow[t]{3}{*}{ Fathers' education level } & Under the Diploma & $5(16.7 \%)$ & $2(4.4 \%)$ & 0.06 \\
\hline & Diploma and Bachelor & $17(56.7 \%)$ & $36(80 \%)$ & \\
\hline & Master and Ph.D. & $8(26.7 \%)$ & $7(15.6 \%)$ & \\
\hline \multirow[t]{2}{*}{ Father's job } & Employed & $30(100 \%)$ & $45(100 \%)$ & \\
\hline & Unemployed & 0 & 0 & \\
\hline \multirow[t]{3}{*}{ Place of residence } & Shiraz city & 10(33.3\%) & $17(37.8 \%)$ & 0.53 \\
\hline & City around & $13(43.3 \%)$ & 14(31.1\%) & \\
\hline & Rural & $7(23.3 \%)$ & $14(31.1 \%)$ & \\
\hline Newborns' birth weight (kg) & & $1892.66 \pm 411.02$ & $1772.88 \pm 331.09$ & 0.16 \\
\hline Pregnancy age (year) & & $34.36 \pm 1.5$ & $34.13 \pm 1.45$ & 0.50 \\
\hline Mothers'age (year) & & $25.80 \pm 5.65$ & $24.53 \pm 5.04$ & 0.31 \\
\hline Fathers'age (year) & & $29.33 \pm 5.58$ & $28.04 \pm 4.22$ & 0.25 \\
\hline
\end{tabular}

Table 2 Comparison of the mean stress before and after the intervention in both groups

\begin{tabular}{|c|c|c|c|c|c|}
\hline $\begin{array}{l}\text { Stress } \\
\text { Group }\end{array}$ & Control & Intervention & Difference of means & $95 \% \mathrm{Cl}$ & $p$-value \\
\hline Before the intervention & $68.28 \pm 13.76$ & $72.96 \pm 12.25$ & -4.67 & {$[-10.87,1.51]$} & 0.13 \\
\hline After the intervention & $71.31 \pm 9.78$ & $57.50 \pm 6.29$ & 13.81 & {$[9.78,17.83]$} & $<0.001$ \\
\hline $\boldsymbol{p}$-value & 0.115 & $<0.001$ & & & \\
\hline
\end{tabular}

Table 3 Comparison of the mean of self-efficacy before and after the intervention in both groups

\begin{tabular}{|c|c|c|c|c|c|}
\hline $\begin{array}{l}\text { Self-efficacy } \\
\text { Group }\end{array}$ & Control & Intervention & Difference of means & $95 \% \mathrm{Cl}$ & $p$-value \\
\hline Before the intervention & $63.66 \pm 7.89$ & $60.83 \pm 4.77$ & 2.833 & {$[-0.37,6.0]$} & 0.057 \\
\hline After the intervention & $60.95 \pm 6.33$ & $70.0 \pm 4.82$ & -9.04 & {$[-11.76,-6.32]$} & $<0.001$ \\
\hline $\boldsymbol{p}$-value & 0.115 & $<0.001$ & & & \\
\hline
\end{tabular}

and anxiety [28-30]. Hospitalization of the newborns resulted in stress in parents, especially mothers. Stress is a natural response to those events creating a feeling of threat, sadness, and lack of balance; however, longterm and high-stress levels can have physical and mental consequences [31, 32]. 
Table 4 Comparison of the study groups by the stress level

\begin{tabular}{llllll}
\hline $\begin{array}{l}\text { Total-Stress } \\
\text { Group }\end{array}$ & N & Mean \pm SD & Mean rank & Sum of rank & Test Statistics \\
\hline Before the intervention & 75 & $70.16 \pm 13.30$ & 33 & 95 & $\boldsymbol{p}=0.009$ \\
After the intervention & 75 & $65.78 \pm 10.90$ & 40 & 87 & $Z=-2.596$ \\
\hline
\end{tabular}

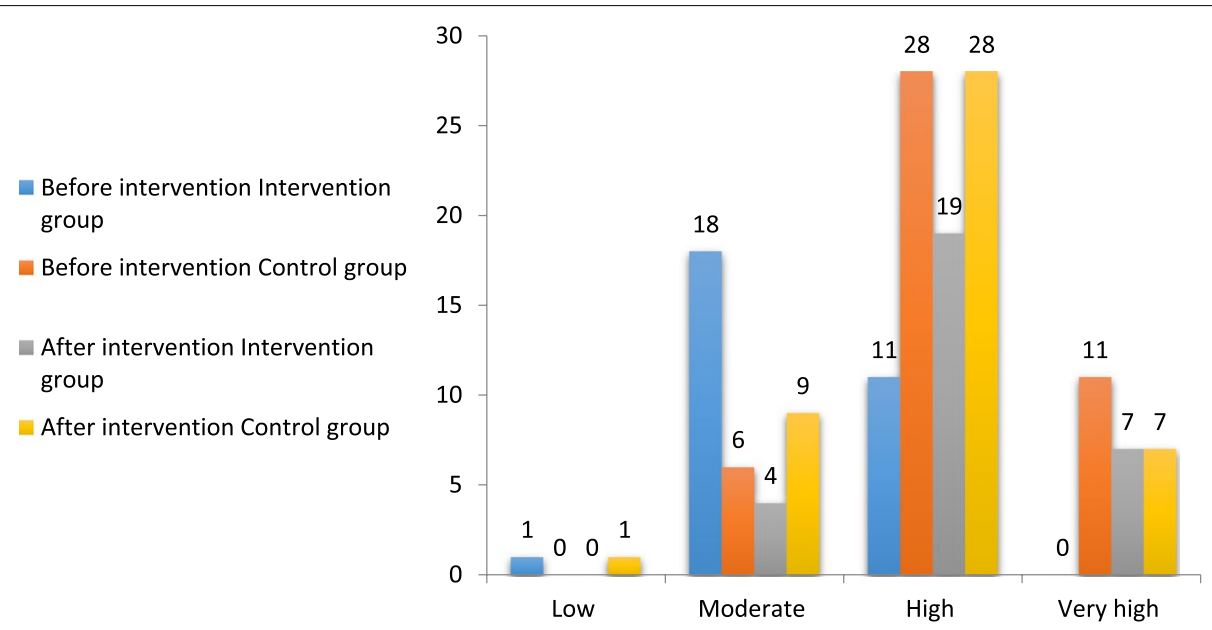

Fig. 2 Comparison of the stress level by group (blue and orange for before intervention; gray and yellow for after intervention)

Arshadi et al. reported that family-based interventions reduce the mothers' anxiety [18]. Also, Jafari et al. investigated the parents' empowerment program's impact on mothers' anxiety and stress with premature newborns. They suggested that mothers' stress and anxiety levels in the intervention group were less than those of the control group [33]. Shaw et al. reported that stress, anxiety, and depression reduced significantly after the supportive interventions in mothers with premature newborns hospitalized in NICU [34]. The results of these studies are consistent with those of our research. The study by Ong et al. indicated stressful conditions of the mothers whose premature infants were hospitalized at NICUs. They concluded that there is a crucial need to decrease their stress by interventional programs [10]. Meijssen et al. investigated the effect of behavioral evaluation of infants and intervention programs on mothers' mental distress with premature newborns within the first 2 years of their lives. They found that mental distress didn't significantly differ in the intervention and control groups [35]. The findings of these researchers are not consistent with those of the present study. The reasons for this discrepancy may be due to differences in the duration of the follow-up.

One of the best and most effective ways to prevent destruction resulting from the hospitalization of premature newborns is to provide caring intervention programs for parents [36]. Any mothers' involvement in infant care can reduce stress because it relieves helplessness and increases their self-efficacy [37]. The relationship between parents and newborns is indirectly affected by that between the parents. For example, those mothers who realize the support and encouragement of their husbands become more interested in performing their parental tasks $[15,16]$. Turan et al. investigated the effect of nursing intervention to relieve mothers' stress in NICUs and found that parents experience high pressure when their infants are needed for intensive care; however, nursing interventions can decrease their stress [38]. Our study showed that a very high-stress level in the control group was more frequent than in the intervention group.

Hosseini et al. performed a clinical trial to determine the effect of relaxation training on improving mothers' breastfeeding self-efficacy with premature newborns. Their results showed that the intervention increased the mothers' breastfeeding self-efficacy [39]. Chan et al. studied the effect of self-efficacy-based breastfeeding training programs. They found that the training increased selfefficacy and breastfeeding duration through 6 months after childbirth [40]. In a study performed by Peyrovi et al. aiming at specifying the effect of mothers' empowerment program on their readiness for premature infant care at the time of discharge from the hospital, it was 
shown that the status of practical and emotional readiness of mothers improved [41]. A study performed by Azmoudeh et al. showed that using self-efficacy promotion sources can improve feeling competent and the maternal role in mothers of Premature Newborns Hospitalized [42]. These results are consistent with those of the present study.

\section{Limitations}

One study's limitation was the relatively small sample size affecting medium and long-term outcomes for both mother and infant. In this regard, we tried not to lose any participants. Our study's design was a non-randomized pre-posttest that could produce bias; then, we selected control and intervention groups sequentially from the two hospitals to reduce the bias.

\section{Conclusion}

This study showed that mothers with premature newborns hospitalized in NICU experience a high level of stress. The main role of mothers in developing the hospitalized premature newborn, taking some measures to reduce their stress and increasing their self-efficacy, seems necessary.

In the present study, training fathers' intervention to support wives reduced their stress and increased their self-efficacy. Thus, taking advantage of fathers' participation in NICU and training them as early intervention NICU purposively is suggested, considering their valuable role in supporting the mothers.

\section{Abbreviations \\ NICU: Neonatal Intensive Care Unit; PSS: Perceived Stress Scale; PMP S-E: Perceived Maternal Parenting Self-Efficacy.}

\section{Acknowledgments \\ Shiraz University of Medical Sciences financially supported this research. The authors would like to thank all the participants and the NICU personnel in Hafez and Nemazee Hospitals for their cooperation. The authors would also like to acknowledge Rozhan Ghobadimoghaddam at the Middle East Techni- cal University to improve the use of English in the manuscript.}

\section{Authors' contributions}

$\mathrm{ZHS}, \mathrm{SB}$, and $\mathrm{HG}$ contributed to the study conception and design. Material preparation, data collection, and data analysis were performed by $\mathrm{ZHS}, \mathrm{SB}, \mathrm{HG}, \mathrm{NS}$, and SMR. The manuscript was written by $S B, Z H S$, and $H G$. All authors read and approved the final manuscript. All authors read and approved the final manuscript.

\section{Funding}

Shiraz University of Medical Sciences financially supported this study.

\section{Availability of data and materials}

The dataset used and analyzed during the current study is available from the corresponding authors upon official request.

\section{Declarations}

Ethics approval and consent to participate

The study was approved by the Institutional Human Ethics Committee of Shiraz University of Medical Sciences (IR.SUMS.REC. 1396.112). Written informed consent forms were obtained from all individual participants included in the study. All procedures performed in this study complied with the institutional and national research committees' ethical standards and the 1964 Helsinki declaration and its later amendments or comparable ethical standards.

\section{Consent for publication}

Not applicable.

\section{Competing interests}

The authors declare that they have no competing interests.

\section{Author details}

'Department of Nursing, School of Nursing and Midwifery, Community Based Psychiatric Care Research Center, Shiraz University of Medical Sciences, Shiraz, Iran. ${ }^{2}$ Student Research Committee, Department of Nursing, School of Nursing and Midwifery, Shiraz University of Medical Sciences, Shiraz, Iran. ${ }^{3}$ Department of Pediatrics, School of Medicine, Neonatal Research Center, Nemazee Teaching Hospital, Shiraz University of Medical Sciences, Shiraz, Iran.

Received: 31 March 2021 Accepted: 20 January 2022

Published online: 04 February 2022

\section{References}

1. Blencowe H, Cousens S, Chou D, Oestergaard M, Say L, Moller A-B, et al. Born too soon: the global epidemiology of 15 million preterm births. Reprod Health. 2013;10(1):1-14. https://doi.org/10.1186/ 1742-4755-10-S1-S2.

2. Organization. WH. Preterm birth. 2018; Available from: http://www. whoint/en/news-room/fact-sheets/detail/preterm-birth. Accessed 3 Sept 2019.

3. Sharifi N, Khazaeian S, Pakzad R. Investigating the prevalence of preterm birth in Iranian population: a systematic review and meta-analysis. J Caring Sci. 2017;6(4):371. https://doi.org/10.15171/jcs.2017.035.

4. Liu L, Oza S, Hogan D, Perin J, Rudan I, Lawn JE, et al. Global, regional, and national causes of child mortality in 2000-13, with projections to inform post-2015 priorities: an updated systematic analysis. Lancet. 2015;385(9966):430-40. https://doi.org/10.1016/S0140-6736(14)61698-6.

5. Najjarzadeh M, Mohammad-Alizadeh-Charandabi S, Abbas-Alizadeh S, Jafarabadi MA, Mirghafourvand M, Tagipour-Amidi N, et al. Validity and reliability of the Iranian preterm birth experiences and satisfaction scale: a methodological and cross-sectional study. Health promotion. Perspectives. 2021;11(1):97-108. https://doi.org/10.34172/hpp.2021.13.

6. Baia I, Amorim M, Silva S, Kelly-Irving M, de Freitas C, Alves E. Parenting very preterm infants and stress in neonatal intensive care units. Early Hum Dev. 2016;101:3-9. https://doi.org/10.1016/j.earlhumdev.2016.04. 001.

7. Huntsinger $E T$, Luecken $L$. Attachment relationships and health behavior: the mediational role of self-esteem. Psychol Health. 2004;19(4):515-26. https://doi.org/10.1080/0887044042000196728.

8. Nystrom K, Axelsson K. Mothers' experience of being separated from their newborns. J Obstet Gynecol Neonatal Nurs. 2002;31(3):275-82. https:// doi.org/10.1111/j.1552-6909.2002.tb00049.x.

9. Fallah Tafti B, Hasanvand S, Salmani N. Study of the amount and tension causes of hospitalized preterm Infants'parents in neonatal intensive care unit. J Pediatr Nurs. 2016;3(1):41-50. https://doi.org/10.21859/jpen-03011 84.

10. Ong SL, Abdullah KL, Danaee M, Soh KL, Soh KG, Japar S. Stress and anxiety among mothers of premature infants in a Malaysian neonatal intensive care unit. J Reprod Infant Psychol. 2019;37(2):193-205. https:// doi.org/10.1080/02646838.2018.1540861.

11. MokE, Leung SF. Nurses as providers of support for mothers of premature infants. J Clin Nurs. 2006;15(6):726-34. https://doi.org/10.1111/j.13652702.2006.01359.x. 
12. Carvalho AE, Linhares MB, Padovani FH, Martinez FE. Anxiety and depression in mothers of preterm infants and psychological intervention during hospitalization in neonatal ICU. Span J Psychol. 2009;12(1):161-70. https://doi.org/10.1017/s1138741600001578.

13. Pancer SM, Pratt M, Hunsberger B, Gallant M. Thinking ahead: complexity of expectations and the transition to parenthood. J Pers. 2000;68(2):25380. https://doi.org/10.1111/1467-6494.00097.

14. Rabiepoor S, Khodaei A, Valizadeh R. Husbands' participation in prenatal care and breastfeeding self-efficacy in Iranian women: a randomized clinical trial. Med J Islam Repub Iran. 2019;33:58. https://doi.org/10.34171/ mjiri.33.58.

15. Holditch-Davis D, Schwartz T, Black B, Scher M. Correlates of mother-premature infant interactions. Res Nurs Health. 2007;30(3):333-46. https:// doi.org/10.1002/nur.20190.

16. Lindberg B, Öhrling K. Experiences of having a prematurely born infant from the perspective of mothers in northern Sweden. Int J Circumpolar Health. 2008;67(5):461-71. https://doi.org/10.3402/ijch.v67i5.18353.

17. Kohan M, Borhani F, Abbaszadeh A, Sultan Ahmadi J, Khajehpoor M Experience of mothers with premature infants in neonatal. J Qual Res Health Sci. 2012:1(1):41-51.

18. ArshadiBostanabad M, NamdarArshatnab H, Balila M, Asghari Jafarabadi $M$, Ravanbakhsh K. Effect of family-centered intervention in neonatal intensive care unit on anxiety of parents. Int J Pediatr. 2017;5(6):5101-11. https://doi.org/10.22038/ijp.2017.22174.1854.

19. Harris AD, McGregor JC, Perencevich EN, Furuno JP, Zhu J, Peterson DE, et al. The use and interpretation of quasi-experimental studies in medical informatics. J Am Med Inform Assoc. 2006;13(1):16-23. https://doi.org/10. 1197/jamia.M1749.

20. Bonell CP, Hargreaves J, Cousens S, Ross D, Hayes R, Petticrew M, et al. Alternatives to randomisation in the evaluation of public health interventions: design challenges and solutions. J Epidemiol Community Health. 2011;65(7):582-7. https://doi.org/10.1136/jech.2008.082602.

21. Handley MA, Schillinger D, Shiboski S. Quasi-experimental designs in practice-based research settings: design and implementation considerations. J Am Board Fam Med. 2011;24(5):589-96. https://doi.org/10.3122/ jabfm.2011.05.110067.

22. Miles MS, Holditch-Davis D, Burchinal P, Nelson D. Distress and growth outcomes in mothers of medically fragile infants. Nurs Res. 1999;48(3):129-40. https://doi.org/10.1097/00006199-199905000-00003.

23. Miles MS, Burchinal P, Holditch-Davis D, Brunssen S, Wilson SM. Perceptions of stress, worry, and support in Black and white mothers of hospitalized, medically fragile infants. J Pediatr Nurs. 2002;17(2):82-8. https://doi. org/10.1053/jpdn.2002.124125.

24. Holditch-Davis D, Miles MS, Burchinal MR, Goldman BD. Maternal role attainment with medically fragile infants: part 2. Relationship to the quality of parenting. Res Nurs Health. 2011;34(1):35-48. https://doi.org/10. 1002/nur.20418.

25. Beheshtipour N, Baharlu S, Montaseri S, Ardakani SR. Comparison of parental stress in premature infants admitted in neonatal intensive care unit (NICU). Sadra Med Sci J. 2017;2(4):361-8.

26. Barnes CR, Adamson-Macedo EN. Perceived maternal parenting selfefficacy (PMP S-E) tool: development and validation with mothers of hospitalized preterm neonates. J Adv Nurs. 2007;60(5):550-60. https://doi. org/10.1111/j.1365-2648.2007.04445.x.

27. Aliabadi F, Borimnejad L, Kamali M, Rassafiani M, Nazi S. Perceived maternal parenting self-efficacy (PMP SE) tool: translation and face validation with Iranian mothers of hospitalized preterm neonates. Iran Rehabil J. 2013:11:7-10.

28. Javanmard GH, Garegozlo RM. The effectiveness of relaxation training on anxiety of disordered children's mothers. Procedia Soc Behav Sci. 2013;84:341-5. https://doi.org/10.1016/j.sbspro.2013.06.563.

29. Segre LS, Chuffo-Siewert R, Brock RL, O'Hara MW. Emotional distress in mothers of preterm hospitalized infants: a feasibility trial of nurse-delivered treatment. J Perinatol. 2013;33(12):924-8. https://doi.org/10.1038/jp. 2013.93.

30. Vakilian K, Khatamidoost F, Khorsandi M. Effect of kangaroo mother care on maternal attachment behavior before. Bimonthly J Hormozgan Univ Med Sci. 2007;11(1):57-63.

31. Kendall-Tackett KA. Intimate partner violence: implications for women's physical and mental health. In: Handbook of women, stress and trauma: Routledge; 2013. p. 139-56
32. Stinson A. Anxiety and stress: how poor performance and absenteeism affect the workplace: Universal-Publishers; 2010.

33. Jafari Mianaei S, Alaei Karahroudi F, Rasouli M. Study of the impacts of rehabilitation program on mothers with premature hospitalized infants. J Ethics Educ. 2013;1(1):29-37.

34. Shaw RJ, St John N, Lilo EA, Jo B, Benitz W, Stevenson DK, et al. Prevention of traumatic stress in mothers with preterm infants: a randomized controlled trial. Pediatrics. 2013:peds. 2013-1331. https://doi.org/10.1542/ peds.2013-1331.

35. Meijssen D, Wolf MJ, Koldewijn K, van Baar A, Kok J. Maternal psychological distress in the first two years after very preterm birth and early intervention. Early Child Dev Care. 2011;181(1):1-11. https://doi.org/10. 1080/03004430903159852.

36. Ghasemi M, Dehdari T, Mohagheghi P, Gohari MR. The effect of educational intervention based on theory of planned behavior (TPB) for improving method of care of premature infant by mother. Razi J Med Sci. 2014;20(115):39-48.

37. Pourkhani S, Chehrzad MM, Reza Masouleh S, Kazem Nezhad Leyli E. The effect of family-based care on stress, anxiety, and depression of mothers with premature infants. Journal of holistic nursing and. Midwifery. 2018;28(2):121-8

38. Turan T, Başbakkal Z, Özbek Ş. Effect of nursing interventions on stressors of parents of premature infants in neonatal intensive care unit. J Clin Nurs. 2008;17(21):2856-66. https://doi.org/10.1111/j.1365-2702.2008. 02307.x.

39. Karbandi S, Hosseini SM, Masoudi R, Mamouri GA. The effect of relaxation training on breastfeeding self-efficacy of mothers with preterm infants: a randomized clinical trial. J Clin Nurs Midwifery. 2014;3(2):37-45.

40. Chan MY, Ip WY, Choi KC. The effect of a self-efficacy-based educational programme on maternal breast feeding self-efficacy, breast feeding duration and exclusive breast feeding rates: a longitudinal study. Midwifery. 2016;36:92-8. https://doi.org/10.1016/j.midw.2016.03.003.

41. Peyrovi H, Mosayebi Z, Mohammad-Doost F, Chehrzad M-M, Mehran A. The effect of empowerment program on "perceived readiness for discharge" of mothers of premature infants. J Matern Fetal Neonatal Med. 2016;29(5):752-7. https://doi.org/10.3109/14767058.2015.1017461.

42. Azmoude E, Jaafarnejad F, Mazloum S. Effect of self-efficacy-based training on maternal sense of competency of primiparous women in the infants care. Evid Based Care. 2014;4(3):7-14. https://doi.org/10.22038/ ebcj.2014.3369.

\section{Publisher's Note}

Springer Nature remains neutral with regard to jurisdictional claims in published maps and institutional affiliations.

Ready to submit your research? Choose BMC and benefit from

- fast, convenient online submission

- thorough peer review by experienced researchers in your field

- rapid publication on acceptance

- support for research data, including large and complex data types

- gold Open Access which fosters wider collaboration and increased citations

- maximum visibility for your research: over $100 \mathrm{M}$ website views per year

At BMC, research is always in progress.

Learn more biomedcentral.com/submissions 